Biol. Proced. Online 2002;4(1): 24-31.

\title{
Mouse Aortic Ring Assay: A New Approach of the Molecular Genetics of Angiogenesis
}

\author{
Véronique Masson ${ }^{1}$, Laetitia Devy ${ }^{1}$, Christine Grignet-Debrus ${ }^{1}$, Sarah Bernt ${ }^{1}$, Khalid Bajou ${ }^{1}$, \\ Silvia Blacher ${ }^{1}$, Guy Roland ${ }^{1}$, Yawen Chang ${ }^{3}$, Timothy Fong ${ }^{3}$, Peter Carmeliet ${ }^{2}$, Jean-Michel \\ Foidart ${ }^{1}$ and Agnès Noël ${ }^{1 *}$
}

${ }^{1}$ Laboratory of Tumor and Developmental Biology, Université de Liège, Tour de Pathologie (B23), Sart Tilman, B-4000 Liège,
Belgium.

${ }^{2}$ Center for Transgene Technology and Gene Therapy, Flanders Interuniversity Institute for Biotechnology, Katholieke Universiteit Leuven, B-3000 Leuven, Belgium.

${ }^{3}$ Rhone-Poulenc Rorer, Hayward, California, 94545, USA.

*To whom correspondence should be addressed: Agnès Noël, Laboratory of Tumor and Developmental Biology, Université de Liège, Tour de Pathologie (B23), Sart Tilman, B-4000 Liège, Belgium. Tel : 0032436625 69; Fax : 00324366 29 36 ; E-mail : agnes.noel@ulg.ac.be

Submitted: May 29, 2002; Revised: June 25, 2002; Accepted: July 17, 2002; Published: October 28, 2002

Indexing terms: Angiogenesis factor; endothelium; transgenic; mice; recombinant adenovirus.

\begin{abstract}
Angiogenesis, a key step in many physiological and pathological processes, involves proteolysis of the extracellular matrix. To study the role of two enzymatic families, serineproteases and matrix metalloproteases in angiogenesis, we have adapted to the mouse, the aortic ring assay initially developed in the rat. The use of deficient mice allowed us to demonstrate that PAI-1 is essential for angiogenesis while the absence of an MMP, MMP-11, did not affect vessel sprouting. We report here that this model is attractive to elucidate the cellular and molecular mechanisms of angiogenesis, to identify, characterise or screen "pro- or anti-angiogenic agents that could be used for the treatment of angiogenesis-dependent diseases. Approaches include using recombinant proteins, synthetic molecules and adenovirus-mediated gene transfer.
\end{abstract}

\section{INTRODUCTION}

Angiogenesis i.e. the sprouting of new blood vessels from preexisting vessels is an essential feature of tissue remodeling associated with at least wound healing, solid tumour development, proliferative retinopathies and rheumatoid arthritis. Extensive interest has been generated to elucidate the cellular and molecular mechanisms involved in the angiogenic process. Different in vivo and in vitro assays have been used so far in order to understand the development of the vascular system, and to screen angiogenic activators and inhibitors. Commonly used in vivo models of angiogenesis include the chorioallantoïc membrane of the chick embryo (CAM assay), the rabbit cornea, the hamster cheek pouch (1) and the Matrigel implant assay $(2,3)$. Despite the relevance of these in vivo assays, systemic inflammatory reactions can lead to interferences that hamper their use for the study of angiogenesis regulation. In vitro cultures of isolated endothelial cells are also useful to study the formation of microvessels but mimic only partially the vascular wall and paracrine interactions between endothelial cells and perivascular cells such as pericytes, smooth muscle cells or fibroblasts which are obviously not taken into account in these models. Nicosia and Ottinetti (4) demonstrated that rat aorta rings reproducibly generate microvessel outgrowths in fibrin or collagen gels, and provide a sensitive assay for the study of angiogenic agonists and antagonists in a chemically defined environment. This system bridges thus the gap between in vitro and in vivo models.

Recently, the generation of transgenic mice allowed to study the impact of gain or loss of function for targeted molecules in various physiological and pathological situations. Genetically altered mice have proven to be valuable tools to study numerous diseases $(5,6)$ and have revealed unanticipated roles for previously characterized proteins involved in angiogenesis $(7,8)$. Paradoxically, $\alpha_{v} \beta_{3}$ and $\alpha_{v} \beta_{5}$ integrins (7) have been proposed as anti-angiogenic agents, whereas the plasminogen

(C) 2002. Biological Procedures Online. Published in Biological Procedures Online under license from the author(s). Copying, printing, redistribution and storage permitted. 
activator inhibitor PAI-1 has been described as a proangiogenic molecule $(8,9)$. These recent findings emphasize the interest of in vitro angiogenic models to gain insight into the molecular mechanisms of angiogenesis. In this context, we have now adapted to the transgenic mouse, the aortic ring assay initially developed in the rat (4). We focused our interest on two enzymatic systems (matrix metalloproteinases or MMPs, and serine-proteases) which play a central role during angiogenesis. These two proteolytic systems control angiogenesis in a cooperate manner by remodeling the extracellular matrix, thereby facilitating endothelial cell migration as well as by releasing matrix-bound angiogenic factors, cleaving cell surface molecules and generating angiogenic factors $(10,11)$.

While the inhibitor PAI-1 appears as an essential element for angiogenesis $(8,9,12,13)$, deficiency in MMP-11 does not affect vessel outgrowth. We demonstrate here the possibility to transduce anti-angiogenic gene into aortic rings by adenovirus.

\section{MATERIALS AND METHODS}

\section{Genetically modified mice}

Homozygous PAI- $1^{-/}$deficient mice and their corresponding wild type (WT) with a mixed genetic background of $87.5 \%$ C57BL6 and 12.5\% $129 \mathrm{SV} / \mathrm{SL}$ strain were generated as described previously (8). MMP- $11^{-/-}$and their corresponding wild type mice with the same genetic background (129 SV/BL6 50/50) were kindly provided by M-C Rio (IGBMC, Strasbourg, France) (14). Mice between 8 and 12 weeks of age of both sexes were used for experiments.

\section{Preparation of the three-dimensional aortic ring cultures}

Angiogenesis was studied by culturing rings of mouse aorta in three-dimensional collagen gels with some modifications of the method originally reported for the rat aorta (4). Thoracic aortas were removed from mice sacrificed by cervical dislocation and immediately transferred to a culture dish containing ice-cold serum-free Minimum Essential Medium (MEM, Life Technologies Ltd., Paisley, Scotland). The peri-aortic fibroadipose tissue was carefully removed with fine microdissecting forceps and iridectomy scissors paying special attention not to damage the aortic wall. One millimeter long aortic rings (approximately 15 per aorta) were sectioned and extensively rinsed in 5 consecutive washes of MEM. Ringshaped explants of mouse aorta were then embedded in a rat tail interstitial collagen gel $(1.5 \mathrm{mg} / \mathrm{ml})$ (15) prepared by mixing 7.5 volumes of $2 \mathrm{mg} / \mathrm{ml}$ collagen (Collagen R, Serva, Heidelberg, Germany), 1 volume of 10 x MEM, 1.5 volume of $\mathrm{NaHCO}_{3}(15.6 \mathrm{mg} / \mathrm{ml})$ and approximately 0.1 volume of $1 \mathrm{M}$ $\mathrm{NaOH}$ to adjust the $\mathrm{pH}$ to 7.4. The collagen gels containing the aortic rings were polymerized in cylindrical agarose wells prepared as previously described (4) and kept in triplicate at $37^{\circ} \mathrm{C}$ in $60 \mathrm{~mm}$ diameter Petri dishes (bacteriological polystyrene, Falcon, Becton Dickinson, Lincoln Park, New Jersey). Each dish contained $6 \mathrm{ml}$ of MCDB131 (Life technologies Ltd., Paisley, Scotland) supplemented with 25 $\mathrm{mM} \mathrm{NaHCO} 3,2.5 \%$ mouse serum, $1 \%$ glutamine, $100 \mathrm{U} / \mathrm{ml}$ penicillin and $100 \mu \mathrm{g} / \mathrm{ml}$ streptomycin. The cultures were kept at $37^{\circ} \mathrm{C}$ in a humidified environment for a week and examined every second day with an Olympus microscope at appropriate magnification.

\section{Quantification of angiogenesis}

To perform image analysis, all images must be taken under the same observation condition (light, contrast, magnification). In this case, processing parameters are fixed once for ever, and image processing became completely automatic.

Image analysis was performed on a Sun SPARC30 workstation with the software «Visilog 5.0 » from Noesis. We used an improved computer-assisted image analysis (16) which allows automatic measurements of the geometrical and morphological parameters. After generation of binary image, the following automatic measurements were performed: the number of microvessels $\left(\mathrm{N}_{\mathrm{v}}\right)$; the maximal microvessel length $\left(\mathrm{L}_{\mathrm{max}}\right)$, and the total number of branching in microvessels $\left(\mathrm{N}_{\mathrm{b}}\right)$.

\section{Fluorescent staining of endothelial cells}

To stain endothelial cells prior to sectioning, rinsing and collagen embedding, aortas were incubated for 4 hours at $37^{\circ} \mathrm{C}$ in a solution of $10 \mu \mathrm{g} / \mathrm{ml}$ fluorescent acetylated low density lipoprotein (Dil-Ac-LDL, acetylated low density lipoprotein labeled with 1,1'-dioctadecyl-3,3, 3',3'tetramethylindocarbocyanine perchlorate, Biomedical Technologies Inc., Stoughton, Massachussets), which is selectively taken up by endothelial cells without affecting their growth rate (17). Cultures were then examined by fluorescent microscopy using rhodamine excitation and emission filters.

\section{Adenovirus-mediated ATF cDNA transfer}

E1E3-deleted adenoviruses directing from the cytomegalovirus (CMV) immediate early promoter expressing the murine Amino-Terminal Fragment of urokinase (ATF) (AdATF) or Escherichia coli $\beta$-galactosidase $($ AdCMV $\beta$ gal $=$ AdLacZ) were propagated as described previously (18). Thoracic aortas were removed from $\mathrm{C} 57 \mathrm{BL} / 6$ mice sacrificed by cervical dislocation and immediately transferred to a culture dish with cold serum-free MEM. The periaortic fibroadipose tissue was carefully removed and each aorta was cut in 2 equal pieces. Pieces of aortas were immediately exposed or not to recombinant adenoviruses at $5 \times 10^{9}$ plaque-forming units in $0.5 \mathrm{ml}$ DMEM in 24 -well plate at $37^{\circ} \mathrm{C}$ in $5 \% \mathrm{CO}_{2}$ (2 pieces of aortas from 2 different mice/condition). After one day of 
infection, aorta were cut in $1 \mathrm{~mm}$-long explants that were extensively rinsed with DMEM, embedded in collagen gel, and cultured with $2.5 \%$ of autologous serum. After 6 days of culture, explants were examined by microscopy and image analysis was performed. To evaluate the efficiency of transduction, WT aortic explants were exposed to AdLacZ, cultured in WT serum for 6 days and fixed for 20 min with cold paraformaldehyde $1 \%$ after removing the agarose around the collagen gel. Aorta rings embedded in collagen were rinsed 3 times quickly with PBS, then rinsed 3 times for 15 min with washing solution (PBS containing $2 \mathrm{mM} \mathrm{MgCl}, 0.02 \%$ Igepal CA-630 and $0.01 \% \mathrm{Na}$ deoxycholate) and finally stained overnight at $37^{\circ} \mathrm{C}$ in the dark in washing solution containing $5 \mathrm{mM} \mathrm{K}_{3} \mathrm{Fe}(\mathrm{CN})_{6}, 5 \mathrm{mM} \mathrm{K}{ }_{4} \mathrm{Fe}(\mathrm{CN})_{6} .3 \mathrm{H}_{2} \mathrm{O}$ and $1 \mathrm{mg} / \mathrm{ml} 5$-bromo4-chloro-3-indolyl- $\beta$-D-galactopyranoside (X-gal; Sigma, St. Louis, MI).

\section{Statistical analysis}

Experiments including four explants per condition were repeated at least twice. Student's t test was used to evaluate whether differences among groups were significant. Statistical significance was set at $p<0.05$.

\section{RESULTS AND DISCUSSION}

\section{Adaptation of rat aortic ring assay to the mice}
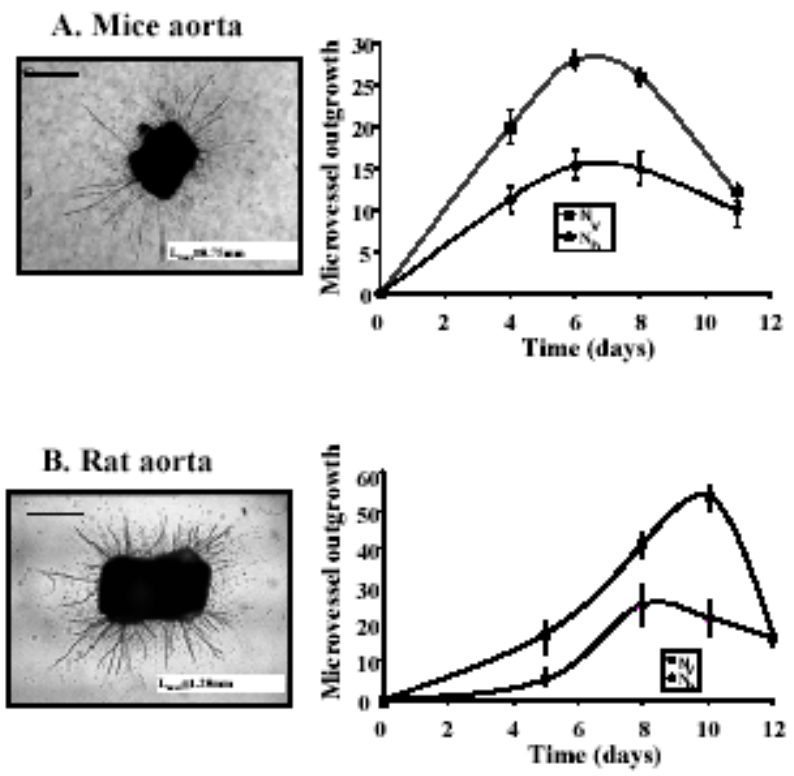

Fig. 1A-B : Microvessel outgrowth from mouse and rat aorta. Photomicrographs showing the maximal angiogenic response of explants isolated either from WT mice (A) cultured in autologous serum (2.5\% final concentration) or from rat (B) cultured in serum-free MCDB131. Bar, $500 \mu \mathrm{m}$. The two angiogenic responses follow the same shape but differ in their time course. Mouse and rat microvessel outgrowth reach their maximal value at day 6 and 10, respectively. Microvessels were quantified by computer assisted image analysis and plotted as a function of the number of days in culture. $\mathrm{N}_{\mathrm{v}}$, number of microvessels; $\mathrm{N}_{\mathrm{b}}$, number of branchings, $\mathrm{L}_{\max }$, maximal microvessel length. $\mathrm{n}=4$; error bars $=\mathrm{SEM}$.

In order to exploit the recent development of transgenic mice, we have adapted to the mouse the rat aortic ring assay in collagen gel. In sharp contrast to the rat system, addition of 2.5 $\%$ mouse serum to MCDB 131 medium was an absolute requisite for microvessel outgrowth from mouse aortic rings. Indeed, serum-free medium failed to support angiogenesis from mouse explants. In the presence of serum, only isolated and dispersed fibroblast-like cells migrated into the gel within the first 4 days of culture (lag phase). Subsequently, microvessel outgrowth arose from the edges of parental vessels (growth phase). The endothelial nature of spreading cells was demonstrated by incubating the aortic ring with Dil-Ac-LDL, which is taken up by endothelial cells.

We have developed a computer-assisted method which allows the measurement of the number of vessels and branchings, as well as their maximal length (16). The initially linear sprouts of endothelial cells progressively branched, anastomosed and formed a microvascular network reaching a maximal complexity at day 6 (Fig. 1A).

In addition to this difference of microvessel sprouting kinetic observed between the two species systems, one should note that the highest number of microvessels was observed with rat aortic rings as compared to the mouse ones $(52 \pm 3$ versus $27 \pm$ 2, respectively) (Fig. 1A and $\mathrm{B}$ ).

The advantage of the rat aortic system is that cultures can be maintained in the absence of serum, in a more chemically defined environment allowing for the evaluation of pro- or anti-angiogenic compounds $(4,16,19)$. Our attempts to culture mouse aortic rings in defined medium supplemented with EGF, bFGF (EGM-2 BulletKit, Biowhittaker, Belgium) were unsuccessful. The main interest of the mouse system is to exploit the recent generation of transgenic mice and to study the consequence of deficiencies, mutations and conditional expression of gene products.

\section{Relevance of the mouse aortic ring assay to study the impact of the gene product deficiency on angiogenesis}

Endothelial cell migration requires extracellular matrix proteolysis, which involves at least two matrix-degrading 
proteases, the plasminogen activator (PA)/plasmin system and the matrix metalloproteinase (MMP) family acting in a concerted manner (10). We recently demonstrated the key role played by the plasminogen activator inhibitor type-1 (PAI-1) during tumour invasion and angiogenesis $(8,9)$. Indeed, the lack of PAI-1 in host mice prevented the local invasion and vascularization of tumours induced by malignant keratinocytes transplantation. In order to evaluate the relevance of the mouse aortic ring assay to study the functions of PAI-1, aortic explants resected from PAI-1-deficient mice or from their corresponding wild type (WT) were embedded in collagen gels in the presence of autologous serum. In contrast to the WT aortic rings from which microvessels spread out (Fig. 2A), no angiogenic response was observed from PAI-1 -/- aortic explants (Fig. 2B). The addition of recombinant PAI-1 used at $10 \mathrm{ng} / \mathrm{ml}$ corresponding to physiological concentration in the plasma, led to a partial restoration of neovessel formation from PAI-1 -/- rings (Fig. 2C) (12).

These data emphasize the central role of PAI-1 played during angiogenesis and confirm the data previously obtained in vivo $(8,12,13)$. We next extended our study to MMP-11, which has been reported to influence the early steps of tumour progression. Indeed, MMP-11 expression promoted the in vivo tumour take (20) and its deficiency was associated with a reduction in tumour development (14). Several MMPs have been reported to play an important role in the early events of cancer progression such as angiogenesis $(11,21,22)$.

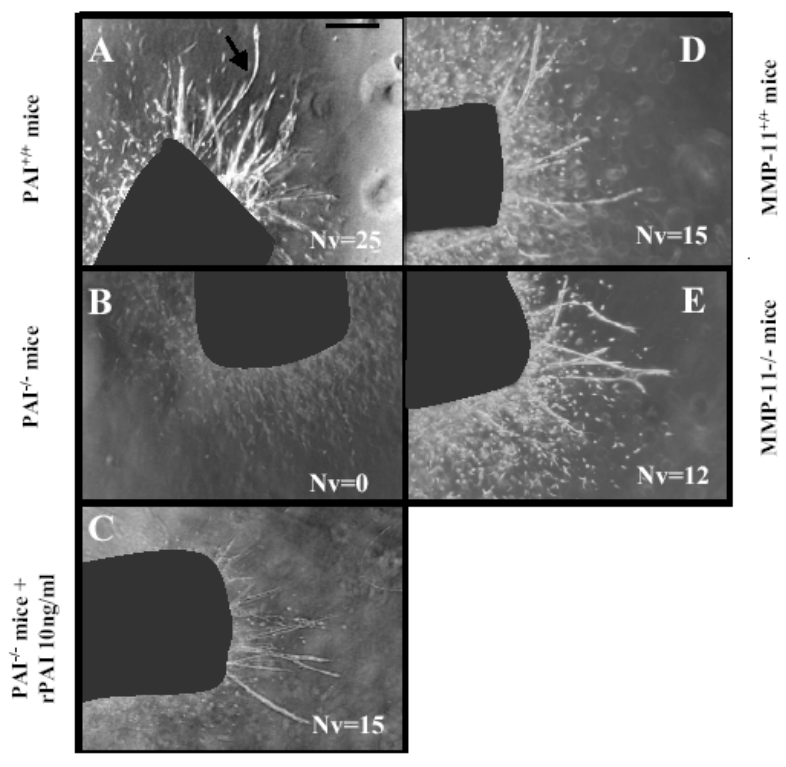

Fig. 2A-E: Angiogenesis is impaired in PAI-1 ${ }^{-/-}$mice and restored by exogenous $\mathrm{PPAI}-1$, while MMP-11 deficiency does not affect vessel outgrowth. Neovessel formation was compared in collagen-embedded explants isolated from WT (A,D), PAI-1 ${ }^{-/-}$(B) and MMP-1 $11^{-/-}(\mathrm{E})$ mice (bar $\left.=250 \mu \mathrm{m}\right)$. Aortic rings were cultured for 6 days in autologous serum. In contrast to WT aortic ring (A), microvessel outgrowth was absent in PAI- $1^{-/}$aortic explants (B) whereas isolated fibroblast-like cells were still present. The addition of $10 \mathrm{ng} / \mathrm{ml}$ recombinant PAI-1 corresponding to plasmatic concentration, led to a partial restoration of neovessel formation from PAI- ${ }^{-1-}$ rings (C). MMP-11 deficiency did not affect angiogenesis (D, E). The arrows delineate capillary outgrowth.

However, so far no data suggest the direct implication of MMP-11 during tumoral angiogenesis. In accordance to this, we clearly demonstrate here that MMP-11-deficiency failed to affect angiogenesis in the aortic ring assay (Fig. 2 D,E).

\section{Adenoviruses-mediated transfer of cDNA into mouse aortic rings}

We next addressed the possibility to deliver and screen pro- or anti-angiogenic agents by using adenoviral vectors, which induce a prolonged gene expression. To attest the adenoviral transduction efficiency, mice aorta were incubated, before embedding into the collagen gel, with recombinant adenoviruses bearing the lacZ gene coding for betagalactosidase (Ad.LacZ). Both endothelial cells and fibroblastlike cells expressed the transgene throughout the study. Interestingly, gene transduction did not affect the angiogenic response (Fig. 3).

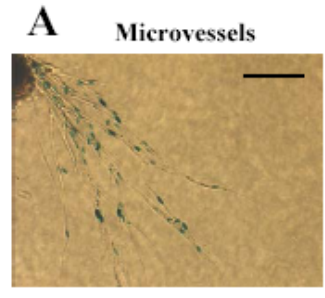

B

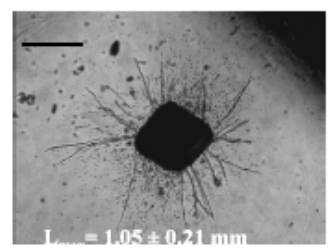

Ad.ATF

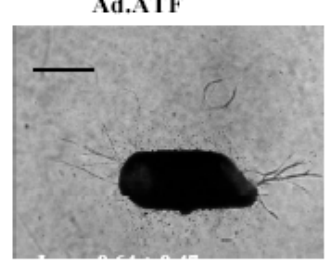

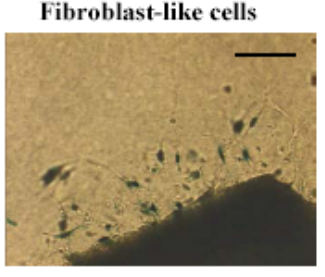

Ad.LacZ
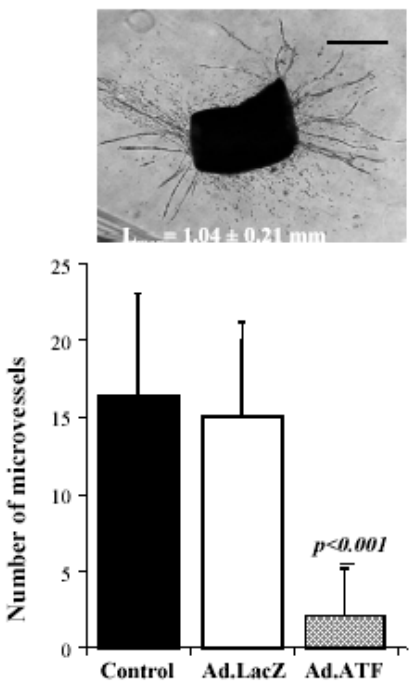

Fig. 3: Microvessel quantification of mouse aortic rings after adenoviral infection. Mouse aortic rings prepared from 
aorta exposed or not to AdLacZ and AdATF were cultured during 7 days. (A) Infection by AdLacZ demonstrated that both branched microvessels and individual fibroblast-like cells were infected by virus and expressed the viral transgene for the duration of the experiment ( $\mathrm{bar}=100 \mu \mathrm{m})$. (B) Pictures of aorta explants were captured from optical microscopy: non infected (left); infected with AdLacZ (middle) or AdATF (right, bar = $250 \mu \mathrm{m}$ ). Image analysis was performed to quantify the number and the maximal length of microvessels. These two parameters are markedly inhibited by AdATF. $\mathrm{L}_{\max }=$ maximal microvessel length. Error bars = SEM.

A large body of evidence validates uPA receptor ( $\mathrm{UPAR}$ ) as a target for cancer therapy. Disruption of the interaction of uPA with UPAR by derivatives of UPA has been shown to reduce tumour growth (23). Li et al. have used an adenoviral vector to deliver and express in vivo the murine uPAR-binding domain of uPA (uPA amino terminal fragment or ATF) (18). Intratumoral injection of these adenovirus into pre-established human or murine tumours arrested tumour growth and vascularization. Accordingly, incubation of aorta with recombinant adenovirus expressing murine ATF (AdATF) drastically inhibited the microvessel outgrowth (Fig. 3). These data confirm the interest of inhibiting uPA-uPAR interaction with ATF to counteract angiogenesis, and demonstrate that gene transfer in the aortic ring assay allows to test the possible therapeutic use of gene products for gene therapy.

Altogether our study demonstrates the adequacy of the mouse aortic ring assay to identify, characterise and screen pro- or anti-angiogenic agents which could be used for the treatment of angiogenesis-dependant diseases.

\section{ACKNOWLEDGEMENTS}

The authors wish to thank Fabrice Olivier for his technical assistance. This work was supported by grants from Communauté Française de Belgique (Actions de Recherches Concertées), the Fonds National de la Recherche Scientifique (FNRS, Belgium), the Fédération Belge Contre le Cancer, the Fonds spéciaux de la Recherche (University of Liège), the Centre Anticancéreux près l'Université de Liège, the FBAssurances and the D.G.T.R.E. from the "Région Wallonne" (Belgium).

K.B. is a recipient of a grant from FNRS-Télévie. A.N. is a Research Senior Associate, L.D. and C.D. are Postdoctoral Research Associates, all from FNRS.

\section{REFERENCES}

1. Folkman J. Toward an understanding of angiogenesis: search and discovery. Perspect Biol Med 1985;29:10-36.
2. Passaniti A, Taylor RM, Pili R, Guo Y, Long PV, Haney JA, Pauly RR, Grant DS, Martin GR. A simple, quantitative method for assessing angiogenesis and antiangiogenic agents using reconstituted basement membrane, heparin, and fibroblast growth factor. Lab Invest 1992;67:519-528.

3. McMahon GA, Petitclerc E, Stefansson S, Smith E, Wong MK, Westrick RJ, Ginsburg D, Brooks PC, Lawrence DA. Plasminogen activator inhibitor-1 regulates tumor growth and angiogenesis. J Biol Chem 2001;276:33964-33968.

4. Nicosia RF, Ottinetti A. Growth of microvessels in serumfree matrix culture of rat aorta. A quantitative assay of angiogenesis in vitro. Lab Invest 1990;63:115-122.

5. Carmeliet P, Collen D. Transgenic mouse models in angiogenesis and cardiovascular disease. $J$ Pathol 2000;190:387-405.

6. Jos Jonkers and Anton Berns. Conditional mouse models of sporadic cancer. Nature Reviews/Cancer 2, 251-265. 2002. Ref Type: Generic

7. Reynolds LE, Wyder L, Lively JC, Taverna D, Robinson SD, Huang X, Sheppard D, Hynes RO, Hodivala-Dilke KM. Enhanced pathological angiogenesis in mice lacking beta 3 integrin or beta3 and beta5 integrins. Nat Med 2002;8:27-34.

8. Bajou K, Noel A, Gerard RD, Masson V, Brunner N, Holst-Hansen C, Skobe M, Fusenig NE, Carmeliet P, Collen D, Foidart JM. Absence of host plasminogen activator inhibitor 1 prevents cancer invasion and vascularization. Nat Med 1998;4:923-928.

9. Bajou K, Masson V, Gerard RD, Schmitt PM, Albert V, Praus M, Lund LR, Frandsen TL, Brunner N, Dano K, Fusenig NE, Weidle U, Carmeliet G, Loskutoff D, Collen D, Carmeliet P, Foidart JM, Noel A. The plasminogen activator inhibitor PAI-1 controls in vivo tumor vascularization by interaction with proteases, not vitronectin. Implications for antiangiogenic strategies. $J$ Cell Biol 2001;152:777-784.

10. Pepper MS. Role of the matrix metalloproteinase and plasminogen activator-plasmin systems in angiogenesis. Arterioscler Thromb Vasc Biol 2001;21:1104-1117.

11. Mikala Egeblad and Zena Werb. New functions for the matrix metalloproteinases in cancer progression. Nature Reviews/Cancer 2, 163-176. 2002. Ref Type: Generic

12. Devy L, Blacher S, Grignet-Debrus C, Bajou K, Masson V, Gerard RD, Gils A, Carmeliet G, Carmeliet P, Declerck PJ, Noel A, Foidart JM. The pro- or antiangiogenic effect of plasminogen activator inhibitor 1 is dose dependent. FASEB J 2002;16:147-154.

13. Lambert V, Munaut C, Noel A, Frankenne F, Bajou K, Gerard R, Carmeliet P, Defresne MP, Foidart JM, Rakic JM. Influence of plasminogen activator inhibitor type 1 on choroidal neovascularization. FASEB J 2001;15:10211027.

14. Masson R, Lefebvre O, Noel A, Fahime ME, Chenard MP, Wendling C, Kebers F, LeMeur M, Dierich A, Foidart JM, Basset P, Rio MC. In vivo evidence that the stromelysin-3 metalloproteinase contributes in a paracrine manner to 
epithelial cell malignancy. J Cell Biol 1998;140:15351541.

15. Montesano R, Orci L, Vassalli P. In vitro rapid organization of endothelial cells into capillary-like networks is promoted by collagen matrices. $J$ Cell Biol 1983;97:1648-1652.

16. Blacher S, Devy L, Burbridge MF, Roland G, Tucker G, Noel A, Foidart JM. Improved quantification of angiogenesis in the rat aortic ring assay. Angiogenesis 2001;4:133-142.

17. Voyta JC, Via DP, Butterfield CE, Zetter BR. Identification and isolation of endothelial cells based on their increased uptake of acetylated-low density lipoprotein. J Cell Biol 1984;99:2034-2040.

18. Li H, Lu H, Griscelli F, Opolon P, Sun LQ, Ragot T, Legrand Y, Belin D, Soria J, Soria C, Perricaudet M, Yeh P. Adenovirus-mediated delivery of a uPA/uPAR antagonist suppresses angiogenesis-dependent tumor growth and dissemination in mice. Gene Ther 1998;5:1105-1113.

19. Zhu WH, Guo X, Villaschi S, Francesco NR. Regulation of vascular growth and regression by matrix metalloproteinases in the rat aorta model of angiogenesis. Lab Invest 2000;80:545-555.

20. Noel AC, Lefebvre O, Maquoi E, VanHoorde L, Chenard MP, Mareel M, Foidart JM, Basset P, Rio MC. Stromelysin-3 expression promotes tumor take in nude mice. J Clin Invest 1996;97:1924-1930.

21. Sounni NE, Devy L, Hajitou A, Frankenne F, Munaut C, Gilles C, Deroanne C, Thompson EW, Foidart JM, Noel A. MT1-MMP expression promotes tumor growth and angiogenesis through an up- regulation of vascular endothelial growth factor expression. FASEB $J$ 2002;16:555-564.

22. Sounni NE, Baramova EN, Munaut C, Maquoi E, Frankenne F, Foidart JM, Noel A. Expression of membrane type 1 matrix metalloproteinase (MT1-MMP) in A2058 melanoma cells is associated with MMP-2 activation and increased tumor growth and vascularization. Int J Cancer 2002;98:23-28.

23. Mazar AP. The urokinase plasminogen activator receptor (UPAR) as a target for the diagnosis and therapy of cancer. Anticancer Drugs 2001;12:387-400. 


\section{PROTOCOLS}

\section{A. Preparation of agarose wells.}

1. Solubilize 1.5g Agarose VII (Sigma, Belgium), in $100 \mathrm{ml}$ MilliQ water and autoclave it (50 min., 1 bar).

2. Run $30 \mathrm{ml}$ of agarose in each sterile $10 \mathrm{~mm}$ tissue culture Petri dish (Falcon).

3. After agarose polymerization, punch rings with $17 \mathrm{~mm}$ puncher first and then a $10 \mathrm{~mm}$ one.

4. Remove the center of the rings and discard it.

5. Grip the ring at its edge with a bowed spatula and lift it up. Place it upside down in a 60 mm Petri dish (bacterial cultures, Nunc).

6. Place 3 rings per dish.

\section{B. Serum preparation.}

1. Sacrifice the mouse by cervical dislocation.

2. Make a vertical midline section of the thorax.

3. Use a pair of scissors to open the heart.

4. Collect as much blood as possible with a sterile Pasteur pipette.

5. Transfer blood to a sterile tube with Clot activator.

6. Leave sample at room temperature for 10-15 $\mathrm{min}$.

7. Centrifuge at 3000 RPM, 5 min. at room temperature.

8. Set sample on ice until use.

\section{Removal of the aorta from the mouse.}

1. Grab the aorta with the forceps and dissect aorta free from the connective tissue with scissors.

2. Cut the aorta at the level of arcus aortica.

3. Transfer aorta to sterile serum-free medium (DMEM (Gibco BRL) with $100 \mathrm{U} / \mathrm{ml}$ penicillin and $100 \mu \mathrm{g} / \mathrm{ml}$ streptomycin (Gibco BRL)\}.

\section{Removal of periaortic fibroadipose tissue from the aorta.}

1. Place aorta on a sterile cork plate covered with aluminum foil and fix it with sterile needles.

2. Remove carefully periaortic fibroadipose tissue.

3. Avoid aorta to dry out by dripping serum-free medium over it.

4. When aorta is clean, place it in another cell culture plate lid with serum-free medium.

5. Cut the aorta with the blade of a scalpel in $1 \mathrm{~mm}$-long rings (about 15 rings/aorta).

6. Transfer the rings to ice cold serum-free medium in a $50 \mathrm{ml}$ tube (Falcon). 
7. At this step explants can be stored for until two hours.

\section{E. Preparation of collagen type I (at $4^{\circ} \mathrm{C}$, in a sterile hood).}

1. Place on ice and in a sterile hood an autoclaved beaker with a magnet on it.

2. Prepare collagen solution by mixing 7.5 volumes of $2 \mathrm{mg} / \mathrm{ml}$ collagen (Collagen R, Serva, Heidelberg, Germany), 1 volume of $10 \mathrm{x}$ MEM (as color indicator), 1.5 volumes of $\mathrm{NaHCO}_{3}(15.6 \mathrm{mg} / \mathrm{ml})$ and approximately 0.1 volume of $1 \mathrm{M} \mathrm{NaOH}$ to adjust the pH to 7.4 .

\section{F. Embedding of aortic rings in collagen type $I$.}

1. Take the $60 \mathrm{~mm}$ Petridish containing the 3 agarose rings (step A).

2. Add $200 \mu \mathrm{l}$ of Collagen type I (step E) and let it polymerize at $37^{\circ} \mathrm{C}$ for $10 \mathrm{~min}$.

3. Add 1 explant per agarose ring on top of the collagen I (on side) and then pour $200 \mu$ of the collagen type I on top of it.

4. Let it polymerise for $10 \mathrm{~min}$ at $37^{\circ} \mathrm{C}$.

5. In each petri dish containing 3 agarose wells add $5.850 \mathrm{ml}$ of MCDB131 (Life technologies Ltd., Paisley, Scotland) supplemented with $25 \mathrm{mM} \mathrm{NaHCO}_{3}, 2.5 \%$ mouse serum $(150 \mu \mathrm{l})$ (step B), 1\% glutamine, and P/S.

6. Incubate at $37^{\circ} \mathrm{C}, 5 \% \mathrm{CO}_{2}$ for 6 days. 